\title{
THE MEASUREMENT OF SEGMENTAL VENOUS FLOW BY AN INDICATOR DILUTION METHOD
}

\author{
BY \\ JOHN SHILLINGFORD, THOMAS BRUCE* AND IVOR GABE
}

From the Medical Research Council Cardiovascular Research Group, Postgraduate Medical School, DuCane Road, London, W.12

Received November 14, 1961

Several methods have been evolved for the measurement of venous flow in animals, but most have a limited application in man as they involve exposure of the appropriate blood vessel. These methods include the Ludwig type stromuhr (Tigerstedt, 1892), the thermostromuhr (Rein, 1928; Schmidt and Walker, 1935; Shipley et al., 1942), the bubble flow meter (Soskin et al., 1934; Brunner, 1948), the differential pressure flow meters (Gregg and Green, 1940; de Burgh Daly, 1926; Johnson and Wiggers, 1937) and the electromagnetic flow meter (Kolin, 1936, 1941).

Fronek and Ganz (1960) report a method for measuring flow in a single blood vessel by a local thermodilution method. They injected a bolus of cool saline into the blood stream and recorded a dilution curve from the change in temperature in the immediate neighbourhood of the injection by a thermistor mounted on the injection catheter. The accuracy of their method was studied in model circulations and in experiments on dogs; good correlation was found with direct methods of measurement. Katsura et al. (1959) endeavoured to measure blood flow using a single thermistor as both heating and the termperature-sensing element. Andres et al. (1954) determined the flow in the human brachial artery by continuous injection of a dye at a constant rate. Peterson et al. (1954) measured the left ventricular output in animals by injecting Evans Blue at a constant rate into the aortic root through a cannula and sampling the resultant mixture in the descending aorta.

The purpose of this paper is to describe a method for measuring local venous flow in man by the injection of an indicator substance under pressure at a constant rate through fine holes in the tip of a double lumen catheter and sampling the diluted blood through the other lumen.

\section{EXPERIMENTS IN VITRO}

\section{Methods}

Catheter and Injection Head. Early experiments involved injection of the indicator through the open end-hole of a standard, $125 \mathrm{~cm}$., No. 9 double lumen cardiac catheter. Although reasonable mixing of the indicator and blood occurred around the end of the catheter at low blood flows, better mixing was obtained by injecting through a specially designed stainless steel head, around the periphery of which were placed three equally spaced holes facing outwards at 45 degrees to the long axis of the catheter (Fig. 1). Through these holes a fine spray of the indicator could be injected under pressure in three directions, sufficient to give adequate mixing in the range of blood flow present in the venous system in man. The injection head screws over the end of the catheter and is secured to it by Araldite. The sampling hole of the double lumen catheter is situated $7 \mathrm{~mm}$. behind the tip of the injection head.

* U.S. Public Health Research Fellow. 


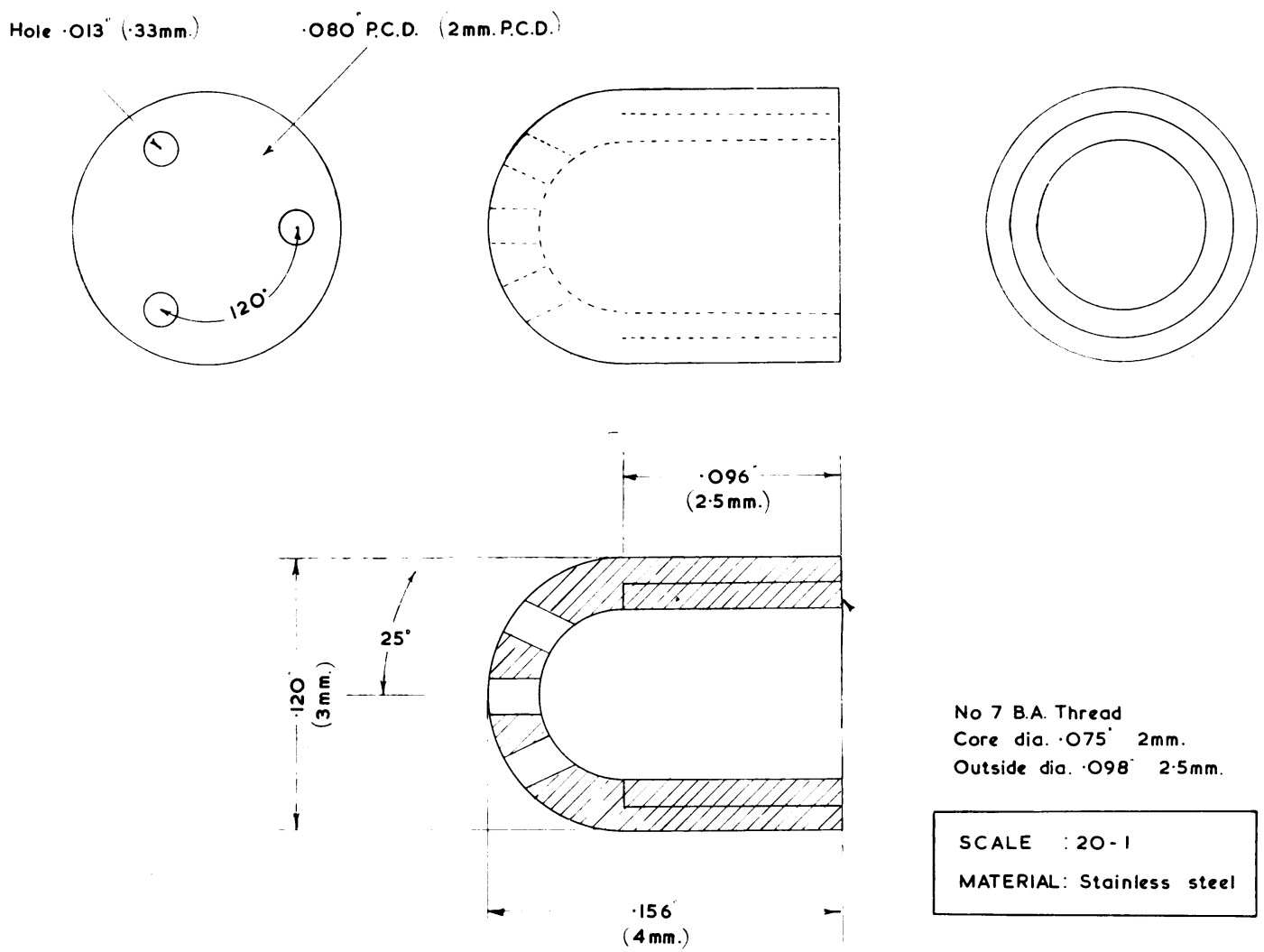

FIG. 1.-The injection head of the catheter; construction diagrams and dimensions.

Injection Syringe and Recording System. It was found necessary, for complete mixing, to inject the indicator substance through the catheter at a high pressure (approximately $100 \mathrm{lb}$. per square inch) and at a constant known rate. To achieve this a special syringe system was designed (Fig. 2). The barrel is made of precision-bore stainless steel with an internal diameter of $1.0 \mathrm{~cm}$. and a length of $54 \mathrm{~cm}$. The plunger is attached to a sliding carriage (Fig. 3) which runs along two guide rails, and is connected by nylon cords, running over pulleys, to a heavy weight which may be varied between 16 and $20 \mathrm{lb}$. The sliding carriage is provided with a brake which, when released, allows the weight to fall and forces the plunger along the barrel. The forward end of the syringe is fitted with a perspex collar through which one may see whether any air bubbles have gained entrance to the syringe; this in turn is connected to the catheter via two three-way taps for filling the syringe with indicator and flushing the catheter.

Adjacent to the guide rails is a recording drum which revolves at one revolution in 60 seconds. A pen which writes on the drum is attached to the sliding mechanism that operates the plunger of the syringe. Thus volume and time of injection are accurately measured and the constancy of injection is continuously monitored.

The trolley table which holds the syringe mechanism is provided with a stand for three drip bottles; one bottle holds the indicator solution and the other two contain flushing solutions. A small bracket near the end of the table holds another three-way tap to which is attached the collection lumen of the catheter, a $5 \mathrm{ml}$. syringe, and a connector from one of the drip bottles.

Experiments in Glass Tubes. Three glass tubes were connected, in turn, to a constant level reservoir containing either water or blood. The tube diameters were $0.9,1 \cdot 2$, and $1.9 \mathrm{~cm}$. A g 


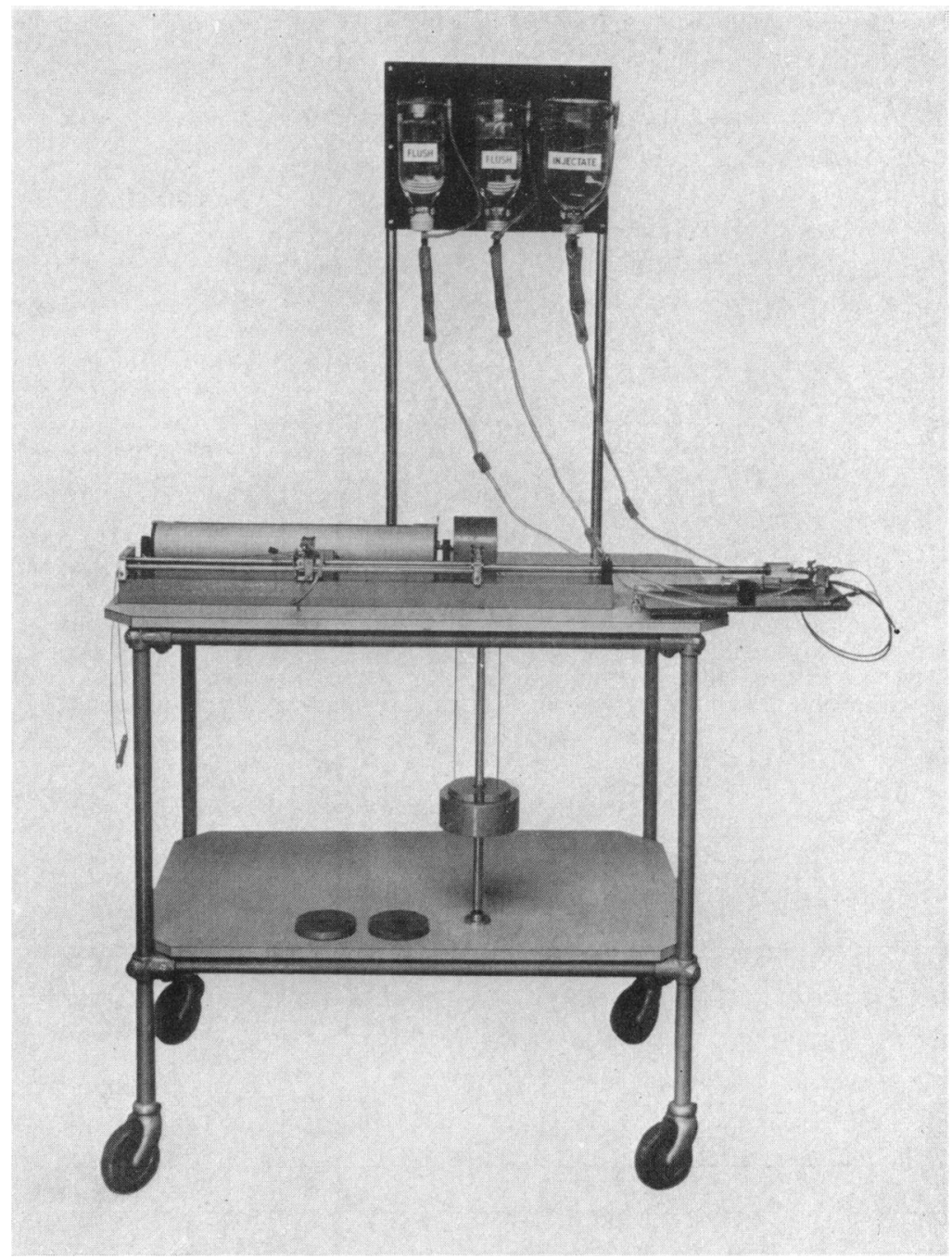

FIG. 2.-The overall view of the injection and recording system. The $16 \mathrm{lb}$. weight which provides the force necessary for injection is seen midway in descent in the centre of the trolley; optional $2 \mathrm{lb}$. weights are lying nearby (see text).

steady flow could be obtained through the tubes over a range of 100 to $6000 \mathrm{ml}$. a minute. Indicator solutions were prepared with approximately $50 \mathrm{mg}$. Coomassie Blue dye (Imperial Chemical Industries, Ltd.) in one litre of water (used for water flows only) or with approximately 10 microcuries of $\mathrm{K}^{131} \mathrm{I}$ in one litre of iodinated water or saline (used for water and blood flows).

The catheter was inserted through a side arm of each of the tubes against the flow of water and indicator was injected at approximately $3 \mathrm{ml}$. a second. Samples of the resulting mixture were simultaneously withdrawn from the collection lumen of the catheter and from the end of the tube. If the concentration of the two samples was the same it was assumed that mixing had been complete and that the sample obtained from the catheter lumen was representative of the final mixture. 


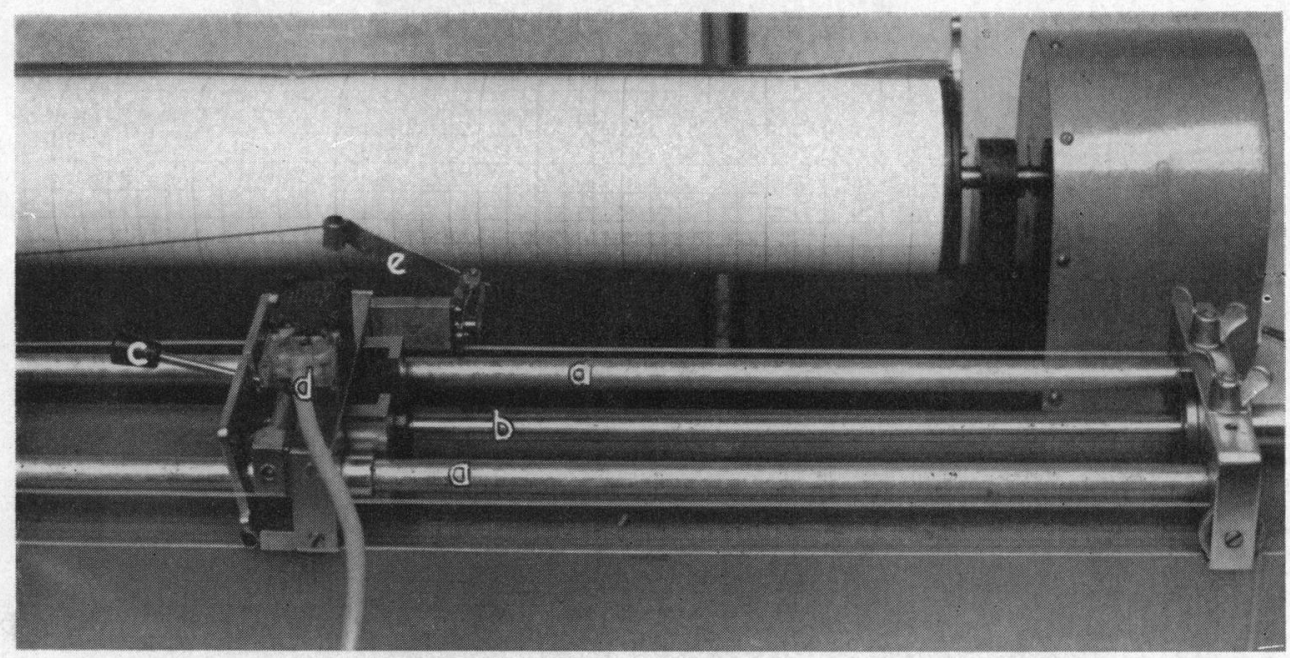

FIG. 3.-Closer view of the sliding carriage which moves on the guide rails (a). The carriage operates the plunger (b) of the injector syringe and provides a base for the breaking mechanism (c), the writing pen (e) and the switch (d) which controls the revolving drum recorder in the background.

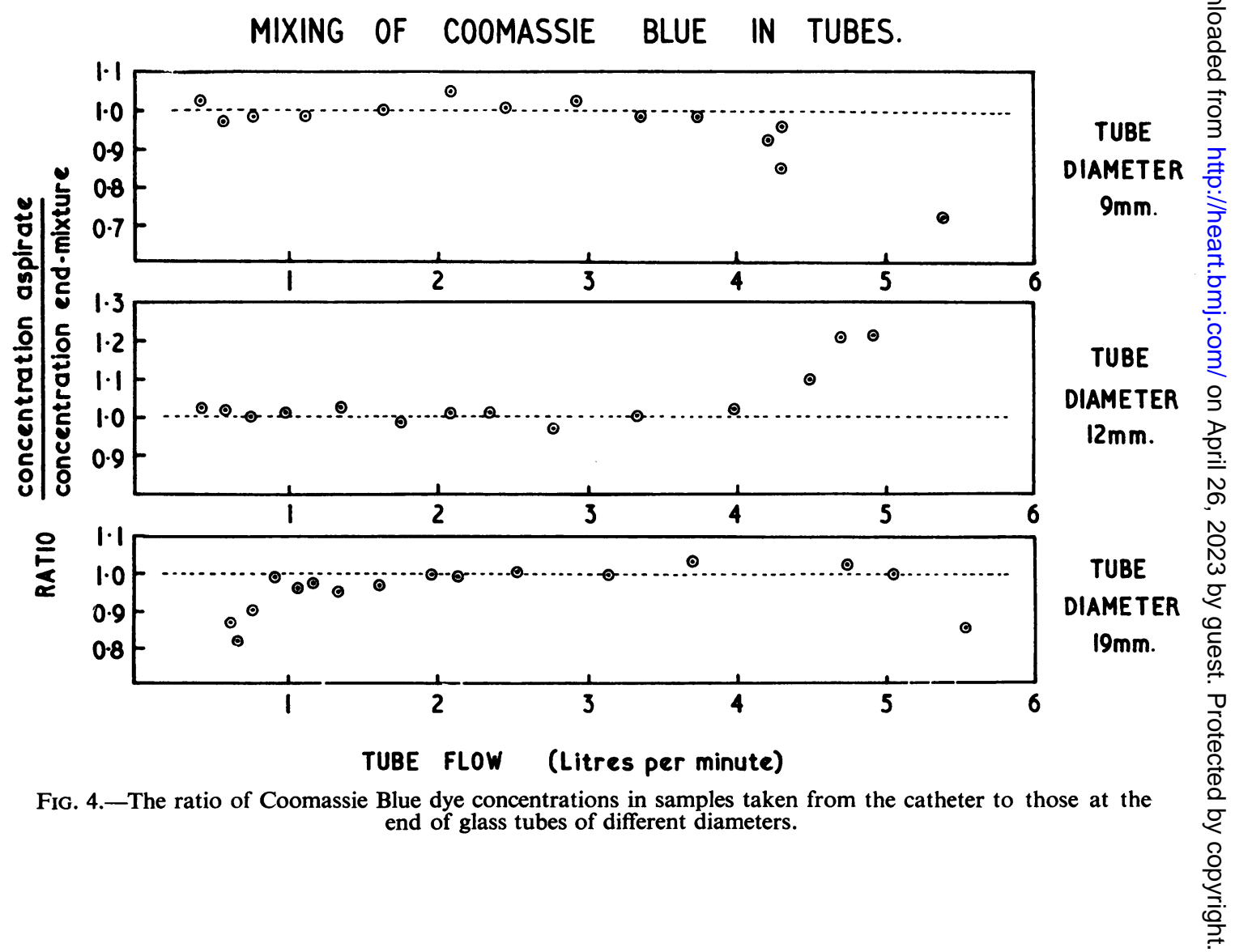


RESULTS

Fig. 4 shows the ratio of the Coomassie Blue concentrations in the aspirate and end-mixture plotted against different rates of flow of water through the tubes. The ratio is near unity for flows up to $4000 \mathrm{ml}$. per minute, this implying that good mixing was obtained; thereafter flow was so fast that incomplete mixing occurred during injection. An unexplained discrepancy was found, however, at flows under one litre per minute in the largest size tube. Similar results were obtained with the radio active indicator. High speed photographs were taken during injection of a Coomassie Blue dye solution, using several rates of water flow, through the $1 \cdot 2 \mathrm{~cm}$. glass tube (Fig. 5). Mixing

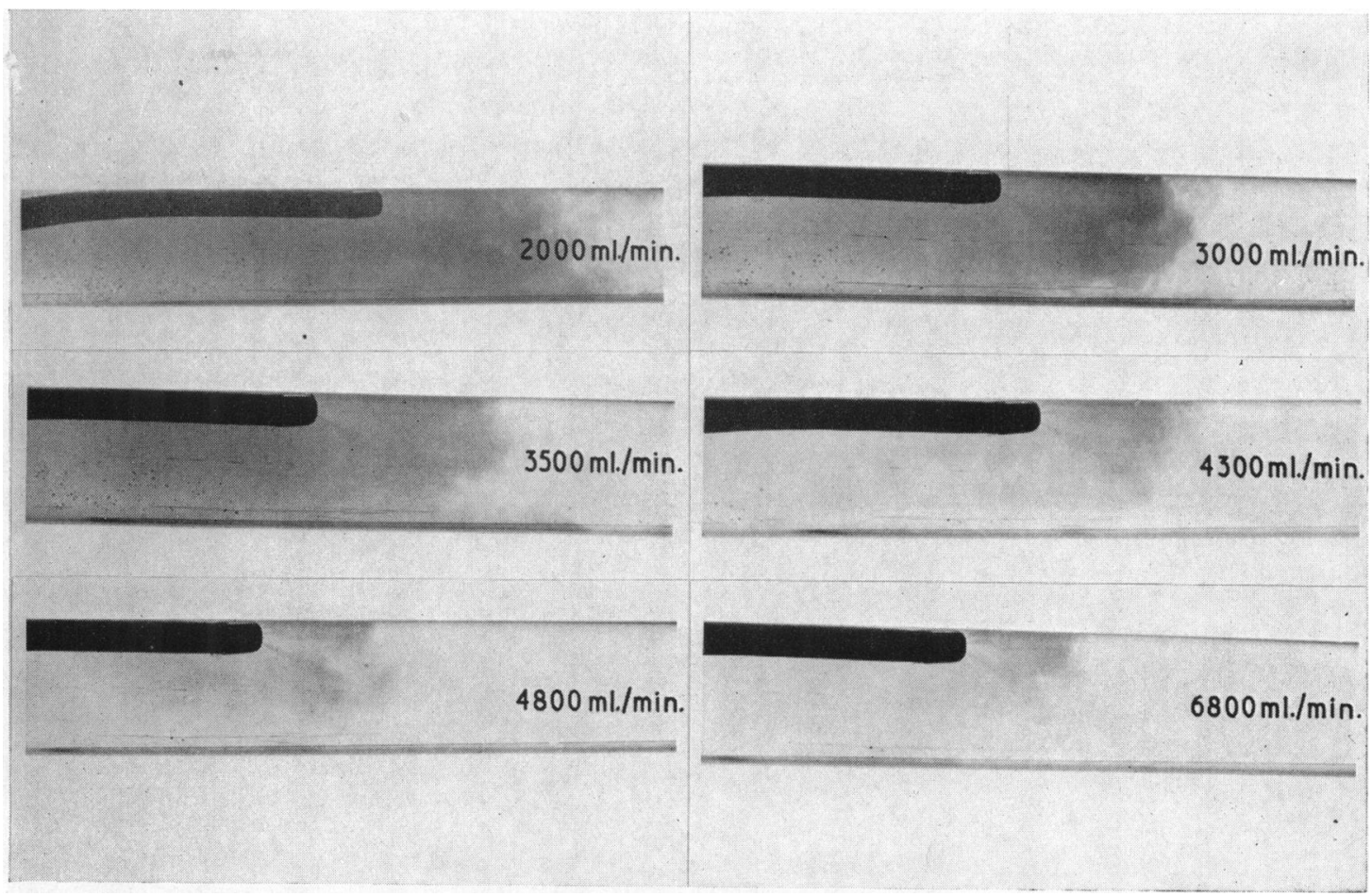

Fig. 5.-High-speed electronic flash photographs of mixing at six different flow rates during injection of an indicator dye (see text).

of the dye and water appeared to be reasonably complete at $3500 \mathrm{ml}$. a minute, but at flows of $4300 \mathrm{ml}$. a minute and higher areas of poor mixing could be seen.

The experiments were repeated with the catheter tip in different positions in relation to the sides of the tube; in the first position the catheter lay along the side wall (as in Fig. 5); in the second in mid-stream; in the third diagonally across the stream with the end pointed against the wall. The mixing effect was essentially the same in each case, in that accurate samples could be obtained up to four litres a minute.

Further tests were made to determine the accuracy of predicted flow in the tubes, calculated by the expression: $F=\frac{C}{c} \times f$, where $F$ is the flow through the tube in ml. a minute (including indicator solution), $C$ is the concentration of indicator injected, $c$ is the concentration of indicator in aspirate, and $f$ is the rate of indicator injection in $\mathrm{ml}$. a minute. 
The flow through the tubes was also determined by measuring the volume collected over a one minute period at the end of the tubes. Fig. 6 shows that the prediction of flow of blood was accurate up to approximately three litres a minute.

\section{TUBE FLOWS}

\section{$K^{131}$ I IN WATER}

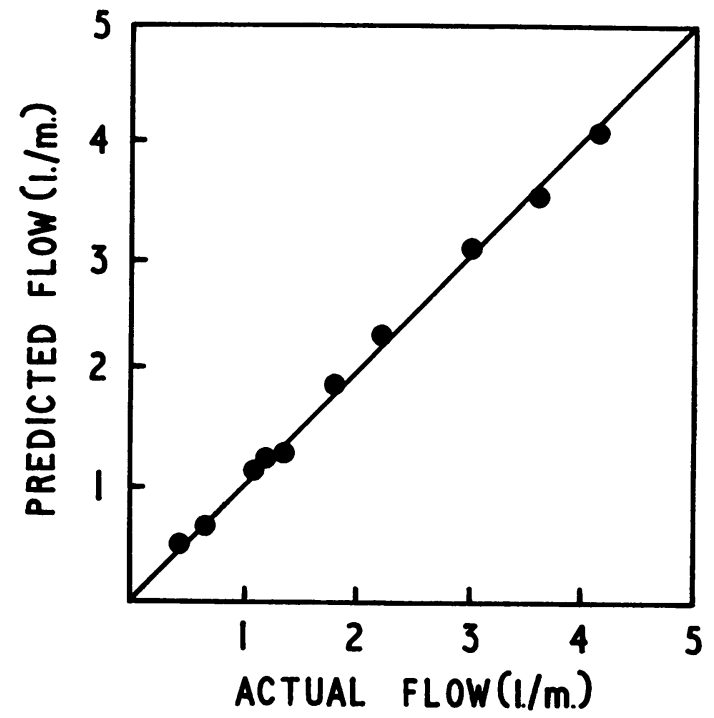

\section{TUBE FLOWS}
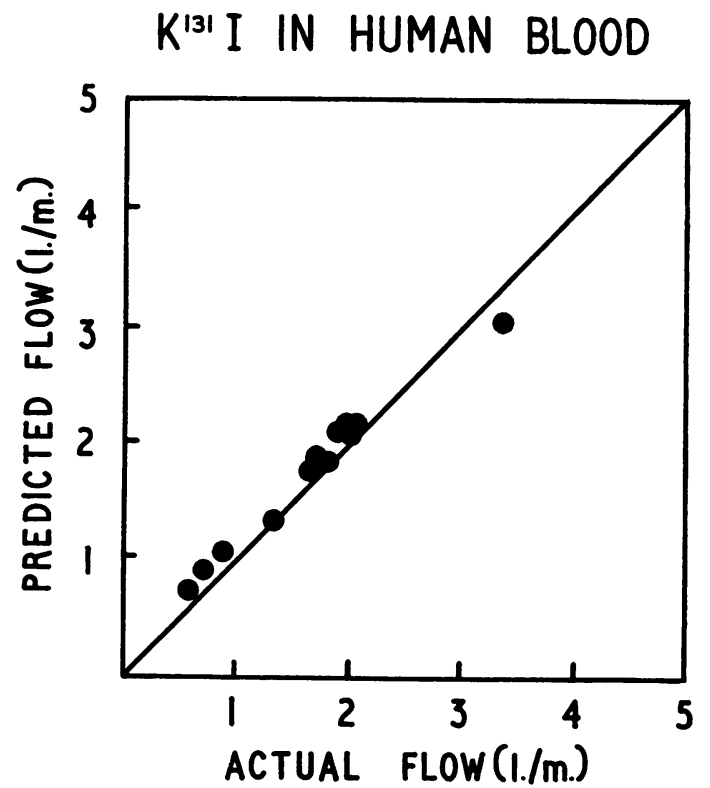

Fig. 6.-Predicted flow rates of water and citrated blood in a glass tube (diameter $1.2 \mathrm{~cm}$.) plotted against actual flow rates. $\mathrm{K}^{131} \mathrm{I}$ was used as an indicator.

\section{Studies in Patients}

\section{MeTHODS}

The opportunity presented for making preliminary studies of segmental venous flow in patients who were undergoing cardiac catheterization for assessment of cardiac disease. The double lumen catheter with injection tip was inserted into the median cubital vein under local anæsthesia and passed under flouroscopic control through the right atrium into the inferior vena cava and down into the iliac veins. Alternatively, it was passed into the internal jugular vein. A wire stylet bent at the end could be placed in the lumen to assist in guiding the catheter into the renal or hepatic veins. Both lumina of the catheter were flushed with a slow drip of normal heparinized saline.

The indicator solution consisted of $500 \mathrm{ml}$. of saline containing 10 microcuries of ${ }^{131}$ I-human serum albumin and an excess of albumin (usually $10 \mathrm{ml}$. of the patient's own plasma) to prevent absorption of the indicator on to the walls of the syringe and catheter.

For each venous flow determination two blood samples were obtained; a baseline control before injection to determine the level of background radioactivity and a sample during continuous injection of the indicator. An injection lasting 6 or 7 seconds provided enough time for withdrawal of an adequate sample. Since the collection lumen was usually filled with saline or 5 per cent dextrose solution, the sample collected had to be corrected for additional dilution. This was done by using numbered, weighed syringes, by weighing the total sample collected, and by knowing the weight of fluid held within the collection lumen of the catheter. The weight of blood in the sample was equal to the weight of the filled syringe less the weights of the empty syringe and the fluid 
in the catheter lumen; the volume of blood was determined by dividing the weight of the blood by the blood specific gravity, which was measured in every case. It can be shown that the concentration of indicator in the blood is equal to the concentration in the diluted sample multiplied by the ratio of the total volume collected to the volume of blood collected; the basic formula, $F=\frac{C}{c} \times f$, could then be used to calculate the venous flow. Determinations could be repeated at two to three minute intervals.

An alternative method for determining venous flow takes advantage of the dilution of the normal blood elements by the indicator solution: the change in hæmatocrit is the simplest of these methods. If this method is used, $F=\frac{H}{H-h} \times f$, where $F$ is the venous flow in ml. a minute, $\mathrm{H}$ is the original hæmatocrit before injection, $h$ is the hæmatocrit after injection of indicator and $f$ is the rate of injection of indicator in $\mathrm{ml}$. a minute.

The potential accuracy of the hæmatocrit method was determined experimentally by comparing the calculated hæmatocrits of known dilutions of whole blood and saline with those actually observed. Fig. 7 shows observed versus predicted dilution factors by the hæmatocrit method.

The true venous flow rate per minute is finally obtained by subtracting the amount of indicator solution injected per minute from the predicted flow. This is the mean value of the flow occurring during the period of the sample collection.

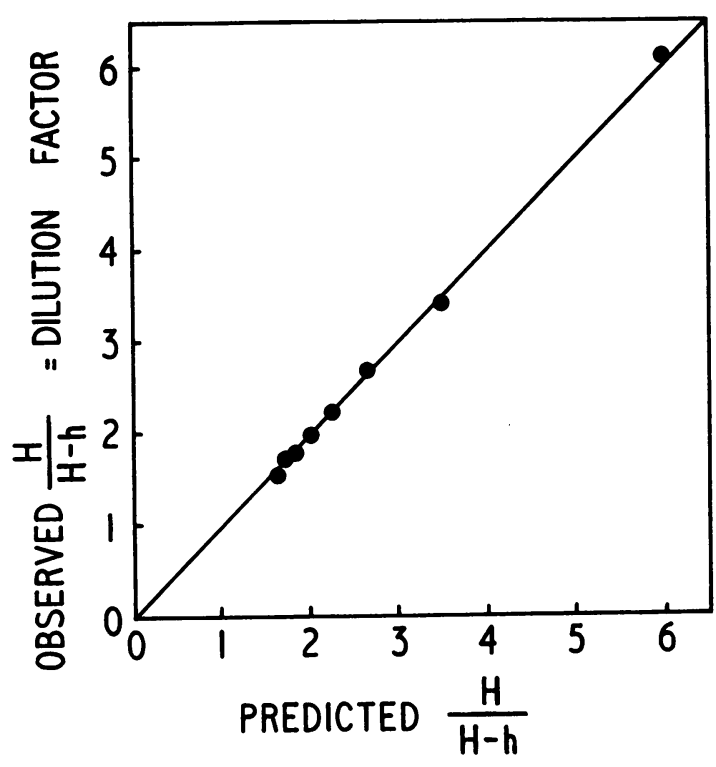

FIG. 7.-Observed hæmatocrit dilution factors $\frac{H}{H-h}$ plotted against those predicted from known test tube dilutions of whole blood and saline.

\section{RESULTS}

The effect of the injection spray was observed under direct vision in the innominate vein of a patient who was having an open chest operation for removal of carcinoma of the lung. The catheter was inserted via the left median cubital vein and passed into the right innominate vein where the stainless steel tip could be seen through the wall. Injection of room temperature normal saline was made at the rate of $2.92 \mathrm{ml}$. a second. No change in the calibre of the vein was seen during repeated injections.

Measurement of venous flow has been made in various sites in five patients. Two had systemic hypertension, one carcinoma of the lung with pulmonary hypertension, one mitral stenosis and one a depressed sternum with postural syncope. Sites where measurement of the venous flow was made included the internal iliac vein, the common iliac vein, the inferior vena cava one inch above the junction of the common iliac veins, the inferior vena cava just above the entry of renal veins, and the internal jugular vein.

Table I summarizes the results. It will be seen that the flow just above the junction of the common iliac veins is approximately twice that of one of its components, and that the renal plus the lumbar flow was approximately equal to that from both common iliac veins. The flow from the right jugular vein was 580 and $620 \mathrm{ml}$. a minute on two occasions in the same patient. 
TABLE I

Estimations of Segmental Venous Flow in Man

\begin{tabular}{|c|c|c|c|c|c|c|}
\hline $\begin{array}{l}\text { Subject } \\
\text { No. }\end{array}$ & $\begin{array}{c}\text { I } \\
\text { External } \\
\text { iliac vein }\end{array}$ & $\begin{array}{l}\text { II } \\
\text { Common } \\
\text { iliac vein }\end{array}$ & $\begin{array}{c}\text { III } \\
\text { Inferior vena } \\
\text { cava one inch } \\
\text { above junction } \\
\text { of common iliac } \\
\text { veins }\end{array}$ & $\begin{array}{c}\text { IV } \\
\text { Inferior vena } \\
\text { cava just above } \\
\text { entry of renal } \\
\text { veins }\end{array}$ & $\begin{array}{c}\text { V } \\
\text { Average renal } \\
\text { and lumbar vein } \\
\text { component } \\
\text { (Column IV } \\
\text { minus III) }\end{array}$ & $\begin{array}{c}\text { VI } \\
\text { Diagnosis }\end{array}$ \\
\hline 1. & & $\begin{array}{l}710(\mathrm{R}) \\
690(\mathrm{H}) \\
750(\mathrm{R}) \\
720(\mathrm{H})\end{array}$ & $\begin{array}{l}1160(\mathrm{H}) \\
1250(\mathrm{H})\end{array}$ & $\begin{array}{c}2150(\mathrm{R}) \\
2280(\mathrm{H}) \\
\overline{-} \\
2040(\mathrm{R}) \\
2360(\mathrm{H})\end{array}$ & 1000 & Hypertension \\
\hline 2. & & $520(\mathrm{H})$ & $\begin{array}{c}900(\mathrm{R}) \\
990(\mathrm{H}) \\
-\overline{(R)} \\
1000(\mathrm{R}) \\
990(\mathrm{H})\end{array}$ & $\begin{array}{l}1830(\mathrm{R}) \\
1700(\mathrm{H}) \\
- \\
2000(\mathrm{R}) \\
2200(\mathrm{H})\end{array}$ & 960 & $\begin{array}{l}\text { Carcinoma of lung } \\
\text { Pulmonary } \\
\text { hypertension }\end{array}$ \\
\hline 3. & $\begin{array}{l}300(\mathrm{R}) \\
290(\mathrm{H}) \\
390(\mathrm{R}) \\
360(\mathrm{H})\end{array}$ & $\begin{array}{l}660(\mathrm{R}) \\
630(\mathrm{H}) \\
580(\mathrm{R}) \\
550(\mathrm{H})\end{array}$ & $\begin{array}{r}840(\mathrm{R}) \\
810(\mathrm{H}) \\
- \\
940(\mathrm{R}) \\
1150(\mathrm{H})\end{array}$ & $\begin{array}{l}2010(\mathrm{R}) \\
1960(\mathrm{H}) \\
-\overline{(R)} \\
2370(\mathrm{R}) \\
2190(\mathrm{H})\end{array}$ & 1200 & Hypertension \\
\hline 4. & & & $\begin{array}{c}1140(\mathrm{R}) \\
1030(\mathrm{H}) \\
- \\
990(\mathrm{R}) \\
980(\mathrm{H})\end{array}$ & 2080 (R) & 1050 & Mitral stenosis \\
\hline 5. & & & $\begin{array}{l}1370(\mathrm{R}) \\
1380(\mathrm{H})\end{array}$ & $\begin{array}{l}2800(\mathrm{R}) \\
2860(\mathrm{H})\end{array}$ & 1460 & $\begin{array}{l}\text { Depressed sternum with } \\
\text { postural syncope }\end{array}$ \\
\hline
\end{tabular}

Determinations made in duplicate and calculated by the radioactive $(\mathrm{R})$ and hæmatocrit $(\mathrm{H})$ techniques.

\section{Discussion}

Although model experiments have shown this method to be accurate over the range of expected flow in the veins of man, several points have to be considered in its application. (1) A true sample of mixed blood may not be obtained when the side hole of the catheter is placed opposite a tributary vessel, the prediction of flow being too large. This can be overcome by making a series of observations at short intervals along the vein. (2) The catheter described can only be used when it is pointing against the stream of flow; it may be possible, however, to design a catheter which will project a spray in a retrograde direction. (3) The volume of blood flow above which complete mixing in tubes will not take place will have an upper limit; fortunately, it is unlikely that this flow will be exceeded under normal physiological conditions in the veins of man. (4) The effect of the spray of the indicator on the vein itself has not yet been fully explored. Although direct observation of the spray injection into the central veins of an anæsthetized patient revealed no visible change in the diameter of the vein, more detailed studies of the application of the method to the intact venous system must still be made.

The method involves no greater risk than that of cardiac catheterization; it is easy to perform and the calculations are simple. Repetition as often as desired is possible up to the limit of permissible radioactive exposure. The method can be used for measuring venous flow wherever it is possible to insert the catheter tip.

One of several indicators may be used in this method including dyes such as Coomassie Blue, Evans Blue or Cardio-green, normal saline with its effect of hæmatocrit or hæmoglobin dilution, 
and radioactive tracers. Although dilution of the blood by saline is an attractive method its accuracy falls off at high flows due to difficulty in reading very small changes in the hæmatocrit and to the magnification of these errors in the flow calculation. Radioactive and dye indicators are more accurate at these high flows. Dyes have the disadvantage that plasma extractions are time consuming and prone to inaccuracies; radioactivity can be quickly determined on the whole blood sample. The dose of $\mathrm{K}^{131} \mathrm{I}$-human serum albumin for each injection is approximately 0.3 microcuries, so that, from the radiation standpoint, many injections may be given.

The accuracy of the local blood flow determination depends on complete mixing of the indicator with the blood in the segment of the vein under examination. It is likely from the model experiments that the spray injection breaks up any streaming in the water or blood and mixes the indicator thoroughly.

The calculations of venous flow in the few patients we have studied seem to give reasonable estimates of the expected flow at these sites. Our results in patients have not, however, been compared with other methods of flow estimation.

\section{SUMMARY}

A method for measuring segmental venous flow by a continuous, local, indicator dilution technique is described, using a double lumen catheter with a spray injection tip. The accuracy has been tested in vitro and the application and limitations of the method in man have been outlined. The results are reproducible and the method is safe for the measurement of flow in any of the veins of man which can be reached by a cardiac catheter.

We should like to thank Mr. C. Lorden and Mr. D. Chappell for the construction of the injection syringe and catheter head and Miss J. Powell for her technical assistance.

\section{REFERENCES}

Andres, R., Zierler, K. L., Anderson, H. M., Stainsby, W. N., Cader, G., Ghrazyib, A. S., and Lilienthal, J. L., Jr. (1954). J. clin. Invest., 33, 482.

Brunner, H. D. (1948). Methods in Medical Research. 80 Year Book Publishers, Chicago.

de Burgh Daly (1926). J. Physiol., 61, 21P

Fronek, A., and Ganz, V. (1960). Circulat. Res., 8, 175.

Gregg, D. E., and Green, H. D. (1940). Amer. J. Physiol., 130, 114.

Johnson, J. R., and Wiggers, C. J. (1937). Amer. J. Physiol., 118, 38.

Katsura, S., Weiss, R., Baker, D., and Rushmer, R. F. (1959). I.R.E. Trans. med. Electron., 6, 283.

Kolin, A. (1936). Proc. Soc. exper. Biol. \& Med., 35, 53.

- (1941). Proc. Soc. exper. Biol. \& Med., 46, 233.

Peterson, L. H., Helrich, M., Greene, L., Taylor, C., and Choquette, G. (1954). J. appl. Phys., 7, 258.

Rein, H. (1928). Ztschr. f. Biol., 87, 394.

Schmidt, C. F., and Walker, A. M. (1935). Proc. Soc. exper. Biol. \& Med., 33, 346.

Shipley, R. E., Gregg, D. E., and Wearn, J. T. (1942). Amer. J. Physiol., 136, 263.

Soskin, S., Priest, W. S., and Schultz, W. J. (1934). Amer. J. Physiol., 108, 107.

Tigerstedt, R. (1892). Skandinav. Arch. f. Physiol., 3, 145. 